\title{
Silymarin Protects Mouse Liver and Kidney from Thioacetamide Induced Toxicity by Scavenging Reactive Oxygen Species and Activating PI3K-Akt Pathway
}

\author{
Shatadal Ghosh, Abhijit Sarkar, Sudip Bhattacharyya and Parames C. Sil* \\ Division of Molecular Medicine, Bose Institute, Kolkata, India
}

Silymarin (SMN) has been shown to possess a wide range of biological and pharmacological effects. Besides, SMN has antioxidant and free radical scavenging activities. Thioacetamide (TAA) is a well-documented liver toxin that requires oxidative bioactivation to elicit its hepatotoxic effect which ultimately modifies amine-lipids and proteins. Our study has been designed in a TAA exposed mouse model to investigate

OPEN ACCESS

Edited by:

David Sacerdoti,

University of Padua, Italy

Reviewed by:

Maria Luisa Del Moral, University of Jaén, Spain

Amedeo Columbano,

University of Cagliari, Italy

*Correspondence:

Parames C. S

parames@jcbose.ac.in; parames_95@yahoo.co.in

Specialty section:

This article was submitted to Gastrointestinal and Hepatic

Pharmacology,

a section of the journal

Frontiers in Pharmacology

Received: 29 August 2016 Accepted: 24 November 2016 Published: 15 December 2016

Citation: Ghosh S, Sarkar A, Bhattacharyya S and Sil PC (2016) Silymarin Protects

Mouse Liver and Kidney from Thioacetamide Induced Toxicity by Scavenging Reactive Oxygen Species and Activating PI3K-Akt Pathway.

Front. Pharmacol. 7:481. doi: 10.3389/fphar.2016.00481 whether SMN could protect TAA-induced oxidative stress mediated hepatic and renal damage. Results suggest that TAA generated reactive oxygen species (ROS), caused oxidative stress and induced apoptosis in the liver and kidney cells via JNK as well as PKC and MAPKs signaling. All these detrimental effects of TAA could, however, be suppressed by SMN which not only scavenged ROS but also induced PI3K-Akt cell survival pathway in the liver and prevented apoptotic pathways in both the organs. Histological studies, collagen staining and DNA fragmentation analysis also supported our results. Combining, we say that SMN possess beneficial role against TAA mediated hepatic and renal pathophysiology.

Keywords: silymarin, thioacetamide, oxidative damage, liver, PI3k/Akt, kidney, MAPKs, apoptosis

\section{INTRODUCTION}

Silymarin (SMN), an extract of Silybum marianum, has well-known hepatoprotective properties (Letteron et al., 1990; Muriel and Mourelle, 1990a). Being a standardized mixture of flavonolignans, including silibinin, silydianin, sosilibinin, and silychristin, SMN shows free radical scavenging property and cell membrane stabilizing activity (Muriel and Mourelle, 1990a,b; Abdel-Moneim et al., 2015; Reina and Martinez, 2016). At the molecular level, it is believed that SMN stimulates RNA and protein synthesis leading to faster regeneration of damaged liver tissue. SMN also modulates TNF- $\alpha$ associated inflammation pathway. However, the vivid molecular pathways through which SMN exerts its effects are still not clear. The present study has been aimed to investigate the effects of SMN during thioacetamide (TAA) induced hepatotoxicity in details. TAA is used as a fungicide and also serves as a source of sulfur in industries and pharmaceuticals (Kadir et al., 2011). Most importantly, it

Abbreviations: ALP, alkaline phosphatase; ALT, alanine transaminase; AST, aspartate transaminase; CAT, catalase; GPx, glutathione peroxidase; GR, glutathione reductase; GST, glutathione S-transferase; LDH, lactate dehydrogenase; PARP, poly (ADP-ribose) polymerase 1; ROS, reactive oxygen species; SOD, superoxide dismutase. 
is a typical hepatotoxin that dose dependently causes centrilobular cell death accompanied by enhanced plasma transaminases and bilirubin. It has been observed that acute exposure with TAA causes necrosis while chronic exposure causes apoptosis in the liver (Moreira et al., 1995). To elicit these effects, TAA requires oxidative bioactivation into its $S$-oxide (TASO) ultimately leading to its chemically reactive $S, S$-dioxide (TASO2) form (Hajovsky et al., 2012). These metabolites are then distributed among several organs including plasma, liver, kidney, adrenals, bone marrow, and other tissues (Barker and Smuckler, 1974) and modify amine-lipids along with proteins leading to further systemic oxidative stress.

Liver plays a crucial role in the metabolic elimination of most of the currently used drugs and many other foreign compounds, thereby making it one of the most viable target organs for toxicity. Therefore, hepatoprotective agents are necessary in clinical therapy to fight against increasing liver toxic injury (Sinha et al., 2007b). Moreover, vast knowledge of the underlying mechanism of hepatotoxicity has to be attained. Unfortunately, necessary studies, in this field, are limited because of the lack of satisfactory experimental models. Nevertheless, some chemical toxins (like carbon tetrachloride, acetaminophen, and TAA) are often used to create experimental hepatocyte injury models in both in vivo and in vitro conditions (Ledda-Columbano et al., 1991; Kucera et al., 2006; Domenicali et al., 2009; Rousar et al., 2009). However, detail mechanism was not investigated thoroughly. Therefore, in the present study, we have taken a detailed mechanistic approach to explore the molecular signaling pathways as well as histopathological examinations to find out how SMN exerts its beneficial effects. It is to be mentioned that, we have also observed renal dysfunctions with the exposure of TAA and investigated this renal toxicity too in details. For this purpose, the protective action of SMN was evaluated on the basis of several parameters like the activity of antioxidant enzymes and cellular antioxidant power (FRAP); increase of the body weight and cellular non-enzymatic antioxidant (GSH) content; amelioration of the tissue damage (histological assessment) and most importantly the interaction of different signaling molecules associated with the ameliorative role of SMN.

\section{MATERIALS AND METHODS}

\section{Materials Chemicals}

Silymarin, TAA, BSA, Bradford reagent, anti-Bcl-2, anti- Bcl-xL, anti-Bad, and anti-Bax antibodies were purchased from Abcam (UK). Other antibodies were purchased from Sigma-Aldrich Chemical Company (St. Louis, MO, USA). Kits for measurement of blood glucose and LDH were purchased from Span Diagnostic Ltd., India. All other chemicals were bought from Sisco Research Laboratory, India.

\section{Animals}

Adequate numbers of adult male Swiss Albino mice weighing 20-25 g were acclimatized under laboratory conditions for 2 weeks before any experiment. Animals were maintained under standard conditions of temperature $\left(23 \pm 2^{\circ} \mathrm{C}\right)$ and humidity $(50 \pm 10 \%)$ with alternating $12 \mathrm{~h}$ light/dark cycle. The animals were given free access to water and fed standard pellet diet (Agro Corporation Private Ltd., Bangalore, India). All the experiments that had been conducted with animals followed the guidelines approved by the IAEC (Institutional Animal Ethical Committee), Bose Institute, Kolkata [IAEC/BI/3(I) cert./2010] and the study had been approved by both CPCSEA (Committee for the Purpose of Control \& Supervision on Experiments on Animals) Ministry of Environment and Forests, New Delhi, India (1796/PO/Ere/S/14/CPCSEA) and IAEC.

\section{Methods}

\section{Experimental Design for in vivo Treatments}

To design the in vivo experimental study the mice were randomly assigned to four groups and treated as follows:

Group 1: Normal group: mice received neither TAA nor SMN, received vehicle only.

Group 2: Silymarin group: mice received only SMN (150 mg/kg body weight in olive oil) orally for 8 weeks (simultaneously with Group 4).

Group 3: Thioacetamide group: mice received TAA injection at a dose of $100 \mathrm{mg} / \mathrm{Kg}$ body weight twice a week for 56 days (Ansil et al., 2011).

Group 4: TAA and SMN group (post-treatment group): mice received SMN (150 mg/kg body weight in olive oil) orally for 8 weeks after TAA administration twice a week for 56 days.

After the experimental periods animals were sacrificed by cervical dislocation and livers and kidneys were collected.

\section{Determination of Dose and Time-Dependent Activity of SMN by ALP Assay}

For this study, mice were randomly distributed into seven groups each consisting of six animals. The first two groups served as normal control (receiving vehicle only) and toxin control (receiving TAA at a dose of $100 \mathrm{mg} / \mathrm{kg}$ body weight thrice a week in citrate buffer, $\mathrm{pH} 4.5$, i.p.), respectively. The remaining five groups of animals were treated with five different doses of SMN (50, 100, 150, 200, and $250 \mathrm{mg} / \mathrm{kg}$ body weight) for 56 days after 3 weeks followed by TAA administration (Figure 1A).

For the time-dependent study, mice were randomly distributed into six groups each consisting of six animals. The first group served as normal control receiving only vehicle and the second group served as toxin control exposed to TAA at a single dose of $100 \mathrm{mg} / \mathrm{kg}$ body weight thrice a week in citrate buffer, $\mathrm{pH} 4.5$, i.p. The remaining four groups of animals were treated with SMN orally at a dose of $150 \mathrm{mg} / \mathrm{kg}$ body weight, once daily for 2, 4, 8, and 12 weeks after the last TAA administration (Figure 1B).

\section{Measurement of Body Weight}

The body weights of all the experimental animals from each group were measured. 

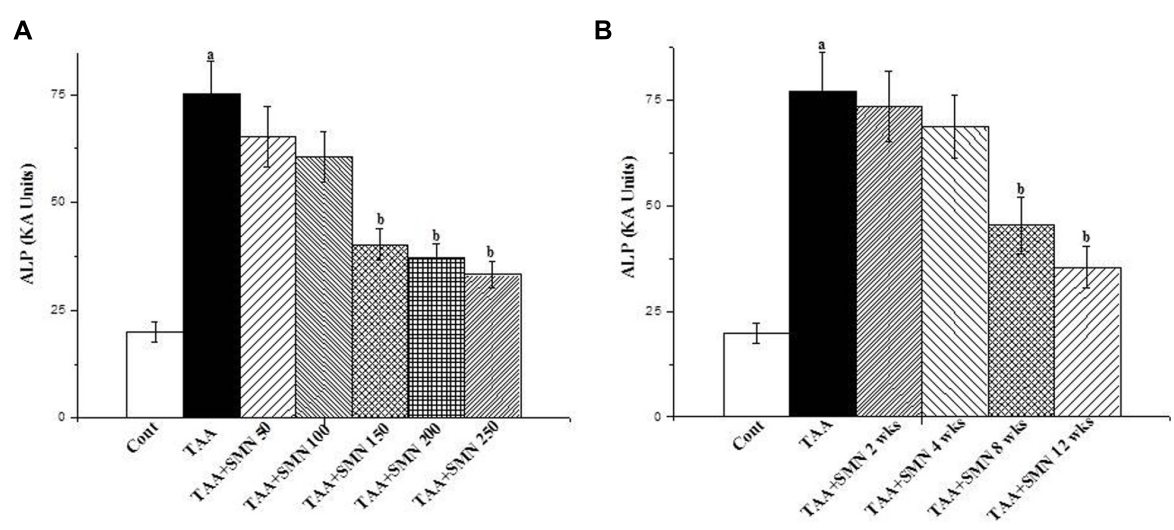

FIGURE 1 | (A) Representation of the dose dependent study of SMN on ALP level in TAA-treated pathophysiology in the serum of the experimental mice. Cont: measurement of serum ALP in normal mice, TAA: measurement of serum ALP in TAA administered mice, TAA+SMN 50, TAA+SMN 100, TAA+SMN 150, TAA+SMN 200, and TAA+SMN 250: measurement of serum ALP in mice which are treated with SMN at a dose of 50, 100, 150, 200, and 250 mg/kg body weight, orally, respectively, after TAA administration at a dose of $100 \mathrm{mg} / \mathrm{kg}$ body weight, i.p. (B) Representation of the time dependent study of SMN on ALP activity in TAA-exposed pathophysiology in the serum of the experimental mice. Cont: measurement of serum ALP in normal mice, TAA: measurement of serum ALP in TAA exposed mice, TAA+SMN 2 week, TAA+SMN 4 week, TAA+SMN 8 week, and TAA+SMN 12 week: measurement of serum ALP in mice which are treated with SMN at a dose of $150 \mathrm{mg} / \mathrm{kg}$ body weight, orally for 2, 4, 8, 12, and 16 weeks, respectively. "a" indicates the significant difference between the normal control and TAA exposed groups, "b" indicates the significant difference between TAA exposed (toxin control) and SMN post-treated groups. Each column represents mean \pm SEM, $n=6 ;\left(p^{\mathrm{a}}<0.05, p^{\mathrm{b}}<0.05\right)$

\section{Preparation of Liver Tissue Homogenate}

Liver tissues from experimental animals were first homogenized $(1: 4, \mathrm{w} / \mathrm{v})$ in ice-cold $0.1 \mathrm{M}$ phosphate buffer $(\mathrm{pH} 7.4)$ containing $2 \mathrm{mM}$ EDTA. The homogenate was later centrifuged at $10,000 \times g$ for $30 \mathrm{~min}$ at $4^{\circ} \mathrm{C}$. The supernatant was collected and recentrifuged at $105,000 \times g$ for $55 \mathrm{~min}$. The subsequent pellets containing microsomal fractions were suspended in $0.25 \mathrm{mM}$ sucrose solution containing $1 \mathrm{mM}$ EDTA and stored at $-80^{\circ} \mathrm{C}$ until further use. The resulting supernatant containing the cytosolic fraction was also collected and used for the experiments. The protein contents of both the cytosolic and microsomal fractions were estimated by the method of Bradford (1976) using crystalline BSA as standard.

\section{Determination of Hepatic and Renal Markers and Nitric Oxide Production}

Specific markers associated with hepatic and renal dysfunction, e.g., AST, ALT, ALP activities, BUN, creatinine, and albumin were estimated by using standard kits. LDH activity was estimated according to the method of Kornberg (1955). The hepatic nitric oxide (NO) level was indirectly assessed using the Griess reaction (Green et al., 1982; Suresh and Das, 2006).

\section{Estimation of Lipid Peroxidation}

Lipid peroxidation in terms of malondialdehyde (MDA) formation was estimated following the method of Esterbauer and Cheeseman (1990).

\section{Assay of Cellular Metabolites}

GSH content was measured, according to the method of Ellman (1959).

GSSG content was estimated following the method of Hissin and Hilf (1976).

\section{Determination of in vivo Antioxidant Power by FRAP Assay}

Ferric Reducing Antioxidant Power assay was performed following the method as described by Benzie and Strain (1999).

\section{Assay of Antioxidant Enzymes}

Activities of different antioxidant enzymes (SOD, CAT, GST, GR, and GPx) have been assessed using the liver tissue homogenates. SOD activity was evaluated as described previously (Manna et al., 2013). One unit of SOD activity could be defined as the enzyme concentration that required to attenuate chromogen production by $50 \%$ in 1 min under the assay conditions.

Catalase activity was estimated by following the decomposition of $\mathrm{H}_{2} \mathrm{O}_{2}$ at $240 \mathrm{~nm}$ for $10 \mathrm{~min}$ according to the method of Bonaventura et al. (1972). One unit of CAT activity is defined as the amount of enzyme, which reduces one $\mu \mathrm{mol}$ of $\mathrm{H}_{2} \mathrm{O}_{2}$ per minute.

Glutathione $S$-transferase activity was assayed based on the conjugation reaction with GSH in the primary step of mercapturic acid synthesis (Habig et al., 1974). GST activity was expressed as $\mu$ moles of $\mathrm{CDNB}$ conjugate formed $/ \mathrm{min} / \mathrm{mg}$ protein.

Glutathione reductase activity was determined following the method of Smith et al. (1988).

Glutathione peroxidase activity was measured according to the method of Flohé and Günzler (1984) using $\mathrm{H}_{2} \mathrm{O}_{2}$ and $\mathrm{NADPH}$ as substrates.

\section{Determination of Radical-Scavenger Activity of SMN in a Cell-Free System} Superoxide radical-scavenging activity

The superoxide radical-scavenging activity of SMN was measured according to the method of Siddhuraju and Becker (2003) and 
Ghosh et al. (2010). Briefly, the reaction mixture contained 0.1 $\mathrm{M}$ phosphate buffer, $\mathrm{pH} 7.4,50 \mu \mathrm{M}$ nitro blue tetrazolium, $468 \mu \mathrm{M}$ NADH, $60 \mu \mathrm{M}$ phenazine methosulfate, and different concentrations of SMN. The mixture was then incubated in the dark for $10 \mathrm{~min}$ at room temperature and the absorbance was read at $560 \mathrm{~nm}$. Results were expressed as percentage inhibition. All experiments were performed in triplicate.

\section{Hydroxyl radical-scavenging activity}

The hydroxyl radical-scavenging activity of SMN was measured according to the method of Nash (1953). Briefly, hydroxyl radicals content was measured by the amount of formaldehyde (detected spectrophotometrically at $412 \mathrm{~nm}$ ) produced from the oxidation of dimethyl sulfoxide (DMSO). All experiments were performed in triplicate.

\section{Nitric oxide radical-scavenging activity}

The nitric oxide radical-scavenging activity of SMN was determined according to the method of Green et al. (1982). The amount of the chromophore formed was detected spectrophotometrically at $540 \mathrm{~nm}$. Results were expressed as percentage. All experiments were performed in triplicates.

\section{DNA Fragmentation Assay}

DNA fragmentation assay was performed following the method of Das and Sil (2012).

\section{Determination of Mitochondrial Membrane Potential $\left(\Delta \psi_{\mathrm{m}}\right)$}

Mitochondria were isolated following the method of Hodârnâu et al. (1973). In short, the membrane potential $\left(\Delta \psi_{\mathrm{m}}\right)$ was measured using a FACS machine with an argon laser excitation at 488 and $525 \mathrm{~nm}$ band pass filter. The evaluation of the mitochondrial membrane potential $\left(\Delta \psi_{\mathrm{m}}\right)$ was determined on the basis of cell preservation of the fluorescent probe JC-1.

\section{Immunoblotting}

Proteins $(50 \mu \mathrm{g})$ from each sample were separated by $10 \%$ SDS-PAGE and transferred into PVDF membranes. Membranes were then blocked using BSA and incubated separately with primary antibodies of anti caspase-3, anti- PARP, and anti-Bcl-xL (1:1000 dilution), anti cytochrome $c$ (1:1000 dilution), anti Bad (1:1000 dilution), anti Bax (1:1000 dilution), anti Bcl-2 (1:1000 dilution), etc., at $4^{\circ} \mathrm{C}$ for overnight. All the primary antibodies were detected against HRP-conjugated secondary antibody using the HRP substrate ECL solution (Sarkar et al., 2016).

\section{Measurement of Hepatic Collagen Content}

Hepatic collagen content was estimated following the method of Gascon-Barré et al. (1989). Briefly, liver sections (15 $\mu \mathrm{m}$ thick) were taken from liver blocks embedded in paraffin and then deparaffinised producing tissue areas of $\sim 50-100 \mathrm{~mm}^{2}$. These were then incubated in $0.04 \%(\mathrm{w} / \mathrm{v})$ solution of fast green in saturated picric acid for about $15 \mathrm{~min}$. After that, all the sections were washed with distilled water, incubated with fast green FCF $0.1 \%(\mathrm{w} / \mathrm{v})$ and sirius red F3B $0.04 \%(\mathrm{w} / \mathrm{v})$ for about $30 \mathrm{~min}$, then washed again with distilled water until the eluted fluid becomes completely colorless. Then $1 \mathrm{ml}$ of $0.05 \mathrm{~N} \mathrm{NaOH}$ in $50 \%(\mathrm{v} / \mathrm{v})$ aqueous methanol was added in each tube and mixed gently. The eluted color was quantified by the help of a spectrophotometer at two wavelengths viz. 530 and $605 \mathrm{~nm}$ (corresponding to the absorbance maxima of sirius red and fast green, respectively).

\section{Isolation of Primary Mouse Hepatocytes}

Hepatocytes were isolated from mice liver by the perfusion technique with collagenase type I at $37^{\circ} \mathrm{C}$ (Sinha et al., 2007a). Only the preparations with $90 \%$ or more viable cells were used for subsequent experiments. Cells were seeded onto culture plates precoated with collagen. Cell density was $2 \times 10^{5}$ cells/well for 24 well plates and $1 \times 10^{6}$ cells/well for six well plates. The cells were cultured and maintained in William's medium E, supplemented with $0.3 \mu \mathrm{M}$ insulin, 10\% FBS, $0.1, \mu \mathrm{M}$ dexamethasone and $1 \%$ streptomycin/penicillin at $37^{\circ} \mathrm{C}, 90 \%$ humidity and $5 \% \mathrm{CO}_{2}$. All experiments were performed $24 \mathrm{~h}$ after cell attachment allowing the formation of a monolayer.

\section{Assessment of Hepatocyte Viability}

Viability of hepatocytes was determined by the MTT assay. Briefly, $250 \mu \mathrm{l}$ of MTT solution $(300 \mathrm{mg} / \mathrm{ml})$ was added to the culture medium $(200 \mu \mathrm{l}$ in each well) $1 \mathrm{~h}$ before the end of $12 \mathrm{~h}$ treatment and incubated at $37^{\circ} \mathrm{C}$ for $30 \mathrm{~min}$. After that, supernatants were discarded and $200 \mu \mathrm{l}$ of DMSO was added and mixed thoroughly to dissolve the crystals. Then, absorbance was taken at 570 and $630 \mathrm{~nm}$.

\section{RNA Extraction and Reverse Transcriptase PCR (RT-PCR)}

RNA was extracted from the liver and kidney tissue of all four groups of mice using the TRIzol reagent, following the manufacturer's protocol (Invitrogen, Carlsbad, CA, USA). The amount of RNA was estimated spectrophotometrically using nanodrop, HellmaTrayCell Type 105.810 (Hellma Analytical). Two microgram of extracted RNA from each sample was converted to cDNA using Thermo Scientific Verso cDNA synthesis kit (Thermo Scientific, USA). Thermal cycling was performed following the sequences: $95^{\circ} \mathrm{C}$ for $5 \mathrm{~min}$ (initial denaturation) followed by the 35 set of cycles: $95^{\circ} \mathrm{C}$ for $30 \mathrm{~s}$ (denaturation), $55^{\circ} \mathrm{C}$ for $30 \mathrm{~s}$ (primer annealing), and $72^{\circ} \mathrm{C}$ for $45 \mathrm{~s}$ (primer extension). After the cycles the time for DNA extension was given $5 \mathrm{~min}$ at $72^{\circ} \mathrm{C}$. After the extension, PCR amplification products were then held at $4^{\circ} \mathrm{C}$ and subjected to electrophoresis on $1.5 \%$ agarose gel.

\section{Histological Studies}

Portions of livers and kidneys were fixed in 10\% v/v neutral buffered formalin solutions for $24 \mathrm{~h}$. Standard techniques were followed for processing the tissue and preparation of paraffin blocks. Fibrosis and necroinflammation were evaluated in sections (5 $\mu \mathrm{m}$ thick) stained with Masson's trichrome and hematoxylin-eosin, respectively, using the Ishak-modified HAI system (Mannan et al., 2014). Mean values were calculated from each of six glomeruli per section.

\section{Statistical Analysis}

All experimental values have been represented as mean \pm S.E.M $(n=6)$. Data on biochemical investigation were analyzed 
using analysis of variance (ANOVA) and the group means were compared by Tukey Test. $P$-values of 0.05 or less were considered significant.

\section{RESULTS AND DISCUSSION}

A number of naturally occurring agents have been studied to assess their hepato-protective roles. In many cases TAA has been used to create a model of hepato-toxicity. These agents include reynosin (Lim et al., 2013), Ginkgo biloba leaves extract (AlAttar, 2012) and ethanolic and aqueous extracts of Phyllanthus acidus (L.) Skeels (P. Acidus; Jain and Singhai, 2011), etc. An imidazolium salt, 1,3-diisopropylimidazolium tetrafluoroborate (DPIM) has also been shown to reduce TAA-induced mouse liver injury (Ding and Zhuo, 2013). Apart from these agents, SMN itself has been shown to possess a remarkable protective effect toward liver as well as other organs. But how SMN exerts its effects are not fully clear especially in case of cellular signaling processes.

In the present study, we investigated whether the acute hepatotoxic and associated nephrotoxic effect of TAA could be prevented or cured by SMN and if yes what molecular pathways SMN uses.

\section{Body Weight and Cellular Leakage}

Figure 2A shows how SMN increases the survival percentage of TAA exposed animals. Figure $\mathbf{2 B}$ shows that TAA exposure significantly reduced the body weight of the experimental animals. SMN, however, could protect mice from this TAA induced weight loss.

Table 1 demonstrates significant elevation of serum ALP, ALT, AST, and LDH activities in the livers and BUN and creatinine levels in the kidneys (Table 2) of the animals exposed to TAA that altered the transport function and membrane permeability of respective organs. Leakage of these enzymes was elevated significantly compared to normal animals upon TAA exposure indicating severe tissue damage. However, the activities of these markers in SMN treated group remained almost the same as normal values. Albumin level was also decreased in TAA exposed group. SMN post-treatment decreased these alleviated values of the hepatic and renal markers toward the normal value.

Nitric oxide level was also increased significantly in TAA exposed animals. This increased NO production due to the oxidative stress caused by TAA exposure, in turn, might induce cell death when $\mathrm{NO}$ interacts with superoxide anion to form peroxynitrite. However, SMN post-treatment effectively lowers NO production (Table 1).

Measurement of lipid peroxidation, a biomarker of oxidative stress, gives a quantitative estimation of ROS mediated cellular injury. SMN treatment significantly inhibited hepatic and renal lipid peroxidation compared to TAA exposed animals (Tables 3 and 4).

\section{Effect on Ferric Reducing Antioxidant Power (FRAP)}

Ferric reducing antioxidant power assay gives an indication of the antioxidant capacity (Benzie and Strain, 1999). In the present study, we performed FRAP assay to evaluate the antioxidant capacities of the hepatic as well as renal tissues of different groups. Results showed TAA exposure caused a significant reduction in FRAP value. However, SMN treatment brought the FRAP value back toward normal (Tables 1 and 4).

\section{Effect on Cellular GSH and GSSG Levels}

Glutathione, a cysteine-containing tri-peptide, is synthesized within the cells from its constituent amino acids and plays a crucial role in maintaining cellular antioxidant capacity. Both the hepatic and renal GSH level decreased in TAA exposed group resulting in the decrease in the GSH/GSSG ratio significantly compared to normal. SMN treatment, however, effectively elevated the level of GSH toward its normal value. In SMN group, the GSH level remained almost the same as normal (Tables 3 and 4).

\section{Effect on Cellular Antioxidant Enzymes}

We have measured the cellular antioxidant enzymes (CAT, SOD, GPx, GR, and GST) believed to fight oxidative stress directly. Results showed the least antioxidant enzyme activities in the

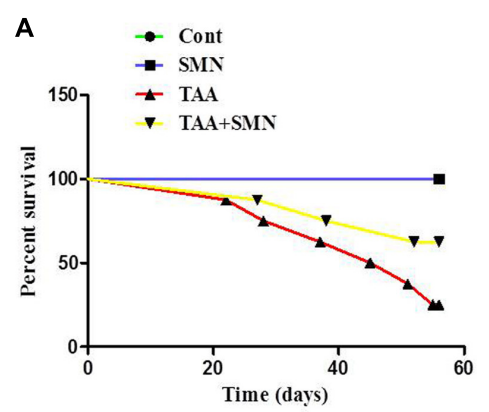

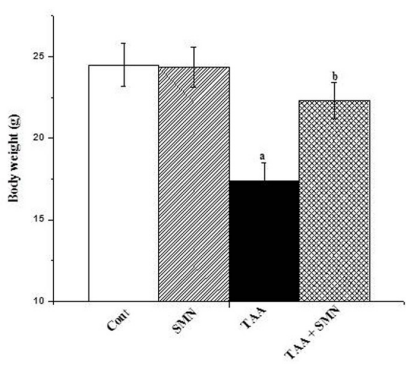

FIGURE 2 | (A) Survival curve of the animals obtained from the data of the 8 weeks study. (B) Effect of silymarin treatment on the body weight of animals of different groups. 
TABLE 1 | Effect of TAA and SMN on liver marker enzymes.

\begin{tabular}{|c|c|c|c|c|}
\hline Parameters & Cont & SMN & TAA & TAA+SMN \\
\hline ALP & $14.45 \pm 1.25$ & $16.36 \pm 1.31$ & $39.12 \pm 2.64^{a}$ & $18.35 \pm 1.51^{b}$ \\
\hline ALT & $58.67 \pm 1.51$ & $69.23 \pm 1.67$ & $140.04 \pm 2.31^{a}$ & $81.75 \pm 2.11^{b}$ \\
\hline AST & $132.78 \pm 4.15$ & $145.65 \pm 5.43$ & $361.73 \pm 7.75^{\mathrm{a}}$ & $213.47 \pm 7.91^{b}$ \\
\hline $\mathrm{LDH}$ & $172.35 \pm 5.35$ & $194.63 \pm 6.19$ & $510.74 \pm 9.68^{a}$ & $247.65 \pm 7.27^{b}$ \\
\hline Albumin & $3.42 \pm 0.06$ & $3.31 \pm 0.07$ & $2.12 \pm 0.10^{a}$ & $2.97 \pm 0.09^{b}$ \\
\hline NO production & $28.05 \pm 0.76$ & $29.03 \pm 0.81$ & $71 \pm 1.78^{\mathrm{a}}$ & $38 \pm 1.13^{b}$ \\
\hline FRAP & $100 \pm 8,91$ & $100 \pm 13.67$ & $100 \pm 67.37^{a}$ & $100 \pm 17.25^{b}$ \\
\hline
\end{tabular}

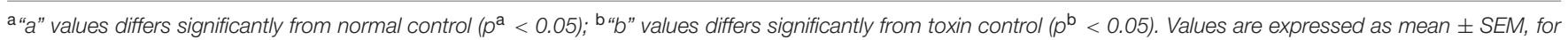
six animals in each group.

TABLE 2 | Effect of TAA and SMN on renal markers.

\begin{tabular}{|c|c|c|c|c|}
\hline Parameters & Cont & SMN & TAA & TAA+SMN \\
\hline Creatinine (mg/dl) & $0.56 \pm 0.01$ & $0.58 \pm 0.01$ & $1.79 \pm 0.036^{a}$ & $0.79 \pm 0.031^{b}$ \\
\hline $\mathrm{BUN}(\mathrm{mg} / \mathrm{dl})$ & $19.12 \pm 0.35$ & $20.13 \pm 0.36$ & $36.46 \pm 0.69^{a}$ & $23.03 \pm 0.39^{b}$ \\
\hline
\end{tabular}

TABLE 3 | Effect of TAA and SMN on antioxidant enzymes activities in liver tissue.

\begin{tabular}{|c|c|c|c|c|}
\hline Parameters & Cont & SMN & TAA & TAA+SMN \\
\hline SOD & $164.59 \pm 2.73$ & $165.59 \pm 3.51$ & $115.25 \pm 4.37^{a}$ & $144.60 \pm 3.29^{b}$ \\
\hline CAT & $154.54 \pm 3.03$ & $156.51 \pm 3.02$ & $87.45 \pm 3.39^{a}$ & $129.14 \pm 2.68^{b}$ \\
\hline GPx & $84.93 \pm 1.25$ & $86.23 \pm 1.88$ & $48.61 \pm 2.13^{a}$ & $75.73 \pm 1.77^{b}$ \\
\hline GR & $40.46 \pm 0.74$ & $40.15 \pm 0.98$ & $18.99 \pm 1.52^{\mathrm{a}}$ & $28.14 \pm 1.41^{b}$ \\
\hline GST & $3.05 \pm 0.05$ & $2.84 \pm 0.06$ & $1.37 \pm 0.08^{a}$ & $2.56 \pm 0.07^{b}$ \\
\hline MDA & $2.59 \pm 0.05$ & $2.57 \pm 0.06$ & $5.34 \pm 0.15^{a}$ & $3.13 \pm 0.16^{b}$ \\
\hline Redox ratio & $9.11 \pm 0.37$ & $8.98 \pm 0.38$ & $4.46 \pm 0.23^{a}$ & $7.36 \pm 0.26^{b}$ \\
\hline
\end{tabular}

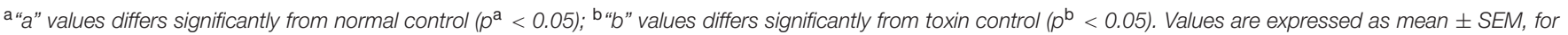
six animals in each group.

TABLE 4 | Effect of TAA and SMN on antioxidant enzymes activities in kidney tissue.

\begin{tabular}{|c|c|c|c|c|}
\hline Parameters & Cont & SMN & TAA & TAA+SMN \\
\hline SOD & $175.45 \pm 5.69$ & $170.37 \pm 5.47$ & $129.34 \pm 6.71^{a}$ & $161.37 \pm 7.36^{b}$ \\
\hline CAT & $132 . .56 \pm 4.61$ & $133.61 \pm 4.54$ & $76.32 \pm 4.03^{a}$ & $117.59 \pm 5.71^{b}$ \\
\hline GPx & $125.91 \pm 6.13$ & $122.03 \pm 5.51$ & $69.23 \pm 4.81^{a}$ & $108.15 \pm 5.13^{b}$ \\
\hline GR & $115.35 \pm 4.12$ & $109.68 \pm 4.05$ & $67.36 \pm 3.79^{a}$ & $98.26 \pm 4.21^{b}$ \\
\hline GST & $3.09 \pm 0.06$ & $2.98 \pm 0.07$ & $1.99 \pm 0.08^{a}$ & $2.65 \pm 0.09^{b}$ \\
\hline MDA & $2.51 \pm 0.1$ & $2.67 \pm 0.14$ & $6.31 \pm 0.41^{a}$ & $3.21 \pm 0.47^{b}$ \\
\hline GSH & $25.08 \pm 1.07$ & $26.13 \pm 1.09$ & $18.32 \pm 0.87^{a}$ & $22.04 \pm 0.97^{b}$ \\
\hline Redox ratio & $32.23 \pm 1.25$ & $32.06 \pm 1.31$ & $21.13 \pm 1.41^{a}$ & $28.38 \pm 1.46^{b}$ \\
\hline FRAP & $100 \pm 4.53$ & $98.65 \pm 4.32$ & $47.25 \pm 5.13^{a}$ & $89.05 \pm 9.33^{b}$ \\
\hline
\end{tabular}

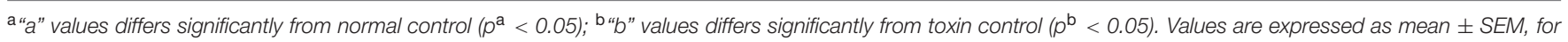
six animals in each group.

TAA group both in case of hepatic and renal tissues (Tables 3 and 4). SMN post-treatment restored those enzyme activities toward the normal value. In the SMN group those values were almost comparable to normal.

The results from the studies performed so far, indicate that TAA administration caused significant amount of oxidative stress in liver and also in kidney. Literature (Natarajan et al., 2006a,b; Amirtharaj et al., 2016) also supports our indication.
But how SMN ameliorates oxidative stress remained unclear. Some earlier reports (Abdel-Moneim et al., 2015) indicated that it could be due to its free radical scavenging capacity. So, we have investigated its different radical-scavenging (hydroxyl, superoxide, and nitric oxide radical) properties in a cell-free system.

The results showed the radical-scavenging properties of SMN itself as evidenced from its hydroxyl, superoxide and nitric oxide radical scavenging ability in a cell-free system. 
A

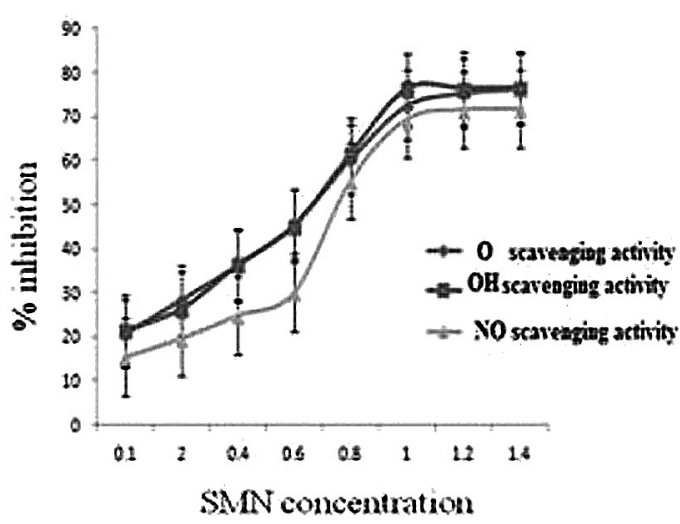

B

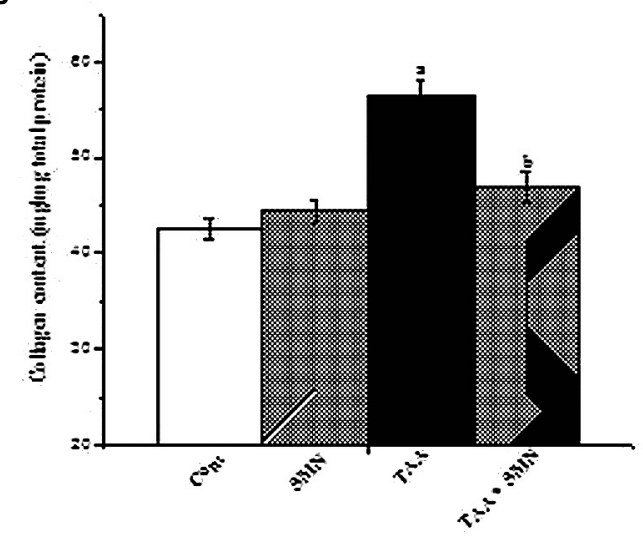

FIGURE 3 | (A) Superoxide radical $\left(\mathrm{O}_{2}^{-}\right)$, hydroxyl radical $\left(\mathrm{OH}_{\bullet}\right)$, and nitric oxide (NO•) scavenging activity of SMN in the cell-free system. Each point represents the mean \pm SEM, $n=6$; (B) Collagen content of liver from various groups of animals.

In short, our experiments indicate that SMN treatment gives protection against the elevation in the level of ROS production as well as NO production in liver and kidney. However, the beneficial effects of SMN may arise partly from its radical scavenging action (Figure 3A).

\section{Collagen Content}

The results of our study showed a significant increase in hepatic and renal collagen content as a result of TAA exposure twice weekly for 8 weeks. SMN treatment, however, decreased the collagen content in liver and kidney, though this effect was not significant in case of kidney (data not shown).

Together all of these results imply that SMN protected mouse liver and kidney against TAA induced pathophysiology mainly by exerting its antioxidant properties (Figure 3B).

\section{TAA-Induced Hepatocellular Apoptosis}

Then, we wanted to know the mode of cell death. So, we have done DNA gel electrophoresis to investigate the nature of cell death (necrosis and/or apoptosis). Results showed that DNA isolated from TAA-exposed mice produced ladder (a hallmark of apoptosis) on the agarose gel. Results suggest the antiapoptotic nature of SMN against TAA-induced hepatic and renal pathophysiology (Figures 4A,B).

\section{Histopathological Findings}

Histopathological studies of the sections from mouse liver exposed to TAA showed (in HE staining) severe tissue damage and vacuolar degeneration. SMN post-treatment attenuated the hepatic injury and showed significant protection of the hepatic cells from apoptotic death. There were no such alterations in SMN group compared to normal (Figure 5A).

Likewise, in case of kidney samples, TAA administration also showed impaired renal morphology including severe tubular epithelial cell death associated with inflammatory cell infiltration and glomerular congestion. SMN post-treatment effectively protected the kidney tissue from these alterations. Only SMN,

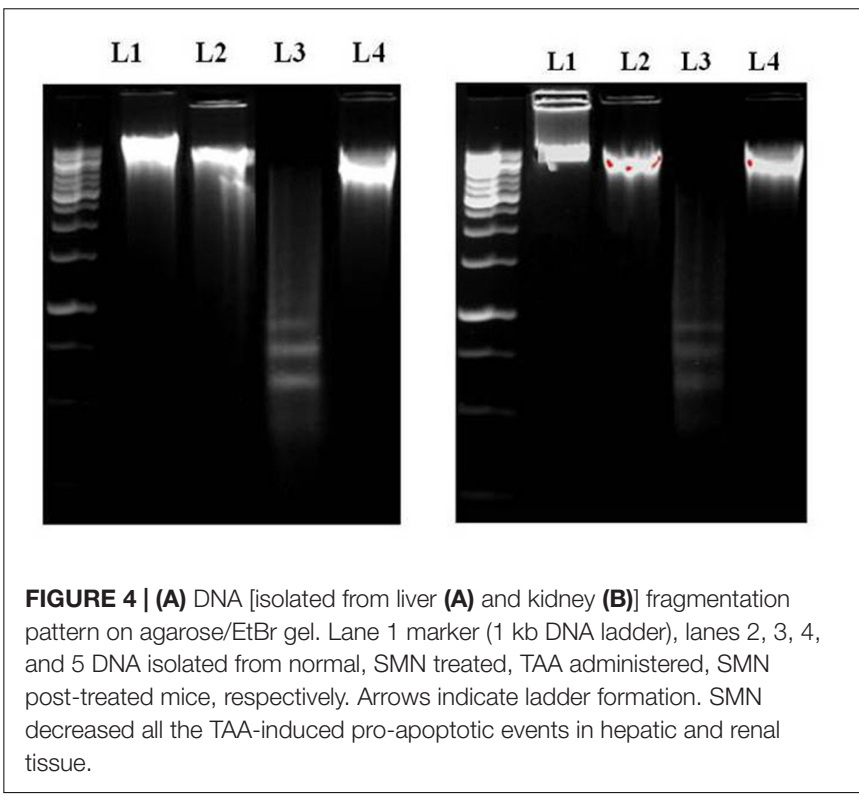

however, did not show any significant change compared to normal (Figure 5B).

In Masson's Trichrome stains, collagen was found to be deposited only in the liver blood vessels in the control and SMN groups. But TAA administration caused a marked increase in collagen accumulation primarily in the periportal regions. However, SMN post-treatment for 8 weeks ameliorated this collagen deposition both in the liver and kidney tissues (Figures 5C,D).

\section{TAA Stimulated Pro-apoptotic Signaling via the Activation of JNK: Protective Role of SMN}

The literature suggests that ROS, produced by the administration of various hepatotoxic agents, can activate JNK (Das et al., 2010; 
A
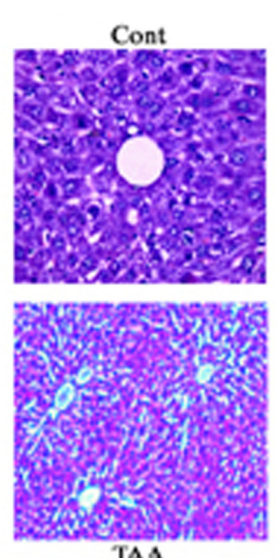

TAA
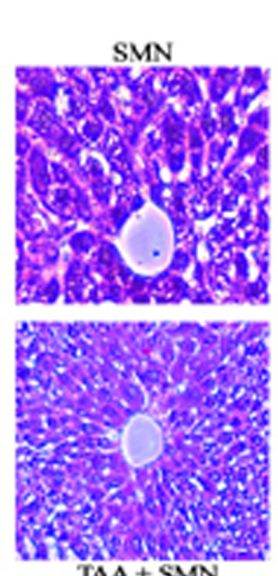

TAA + SMN
B
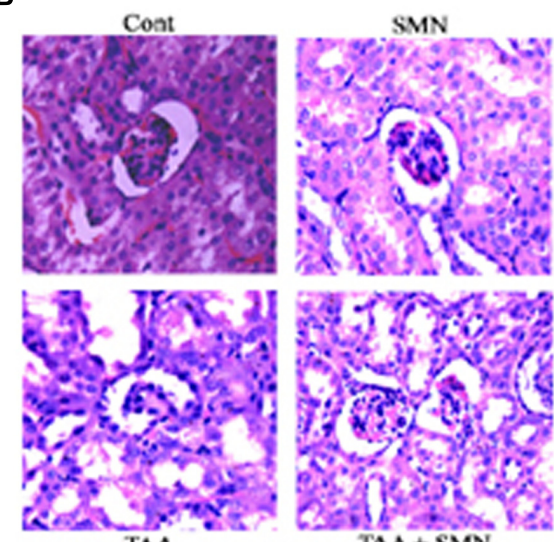

TA

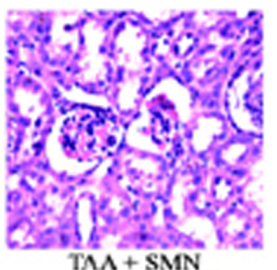

C
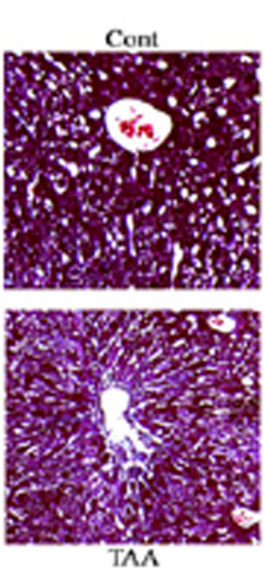
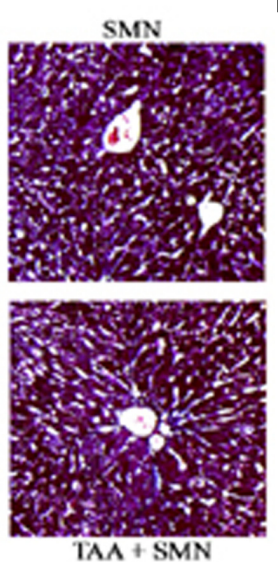

D
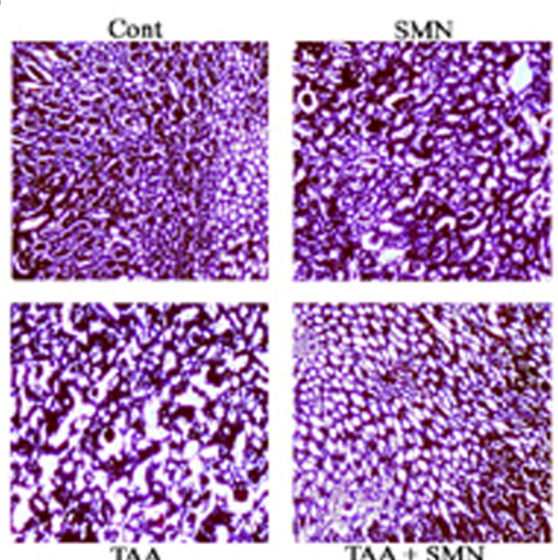

TAA

FIGURE 5 | Histological observations. Hematoxylin and eosin staining of liver (A) and kidney (B). Cont: normal tissues (10x); TAA: TAA exposed (100 mg/kg body weight for 56 days) tissues (10x); SMN: SMN treated (150 mg/kg body weight for 56 days) tissues (10x); TAA + SMN: tissues from animals treated with SMN (150 mg/kg body weight in olive oil orally for 8 weeks) after TAA administration twice a week for 56 days (10x). Masson's Trichrome staining of liver (C) and kidney (D). Cont: normal tissues (10x); TAA: TAA exposed (100 mg/kg body weight for 56 days) tissues (10x); SMN: SMN treated (150 mg/kg body weight for 56 days) tissues (10x); TAA + SMN: tissues from animals treated with SMN (150 mg/kg body weight in olive oil orally for 8 weeks) after TAA administration twice a week for 56 days $(10 \times)$.

Du et al., 2014; Pal et al., 2015a). So, we first checked the level of JNK. Our result showed elevated level of JNK in TAA group. Two pathways may activate JNK. One of them involves oxidation of kinase inhibitors sequestering JNK or upstream molecules like ASK1. Alternatively, sustained JNK activation can be the result of inactivation of JNK phosphatases by ROS. Then, we wanted to check whether SMN could inhibit the phosphorylation and thereby activation of JNK as previous results showed that SMN treatment effectively inhibited JNK activation (Kim et al., 2016). JNK activation might be a potential regulator of mitochondrial permeabilization (Ghosh et al., 2010; Zhao et al., 2014). Phosphorylated JNK in turn phophorylates Bcl-2 family proteins such as Bcl-2 and Bcl-xL (Ma et al., 2014; Kim et al., 2015). Active Bcl-2 (unphosphorylated) maintains the balance between pro and anti-apoptotic proteins. So, once it is phosphorylated, that balance is lost and mitochondrial membrane depolarises resulting in pore formation starts ultimately leading to apoptosis. The result of our study showed that SMN post-treatment prevented the phosphorylation of Bcl-2 and resulting apoptosis (Figure 6).

\section{The Role of PI3K-Akt Cell Survival Pathway}

The PI3K-Akt Pathway is a signaling pathway that regulates cell survival and growth in response to extracellular signals. Literature suggests that the PI 3-kinase/Akt signaling pathway plays an important role in cell survival in liver (Jiang et al., 2014; Rawat and Bouchard, 2015; Saha et al., 2016).

Recent report (Hawkins and Stephens, 2016) also suggest that class 1 PI3Ks, composed of a regulatory subunit p85 and a catalytic subunit $\mathrm{p} 110$, is stimulated by activated receptor tyrosine kinase (RTK). RTKs are activated by the 


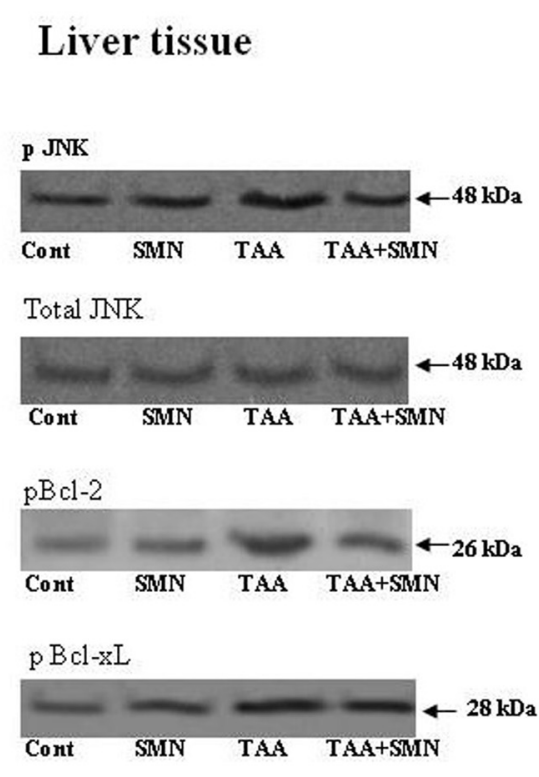

Hepatocytes

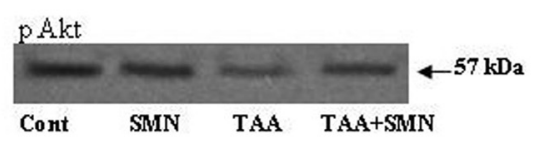

Total Akt

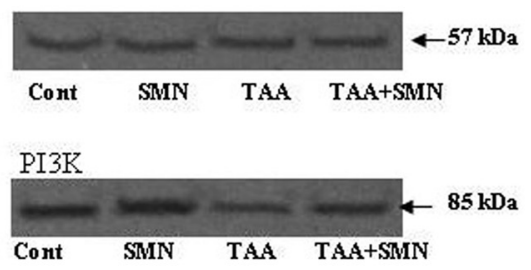

Caspase 8

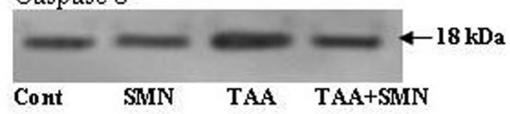

Fas

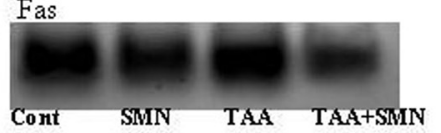

Fas L
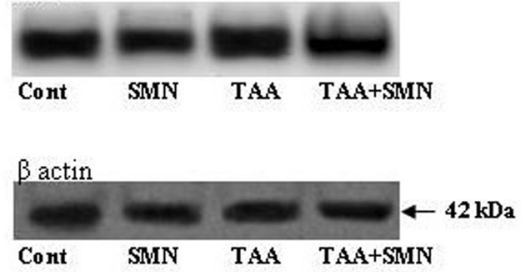
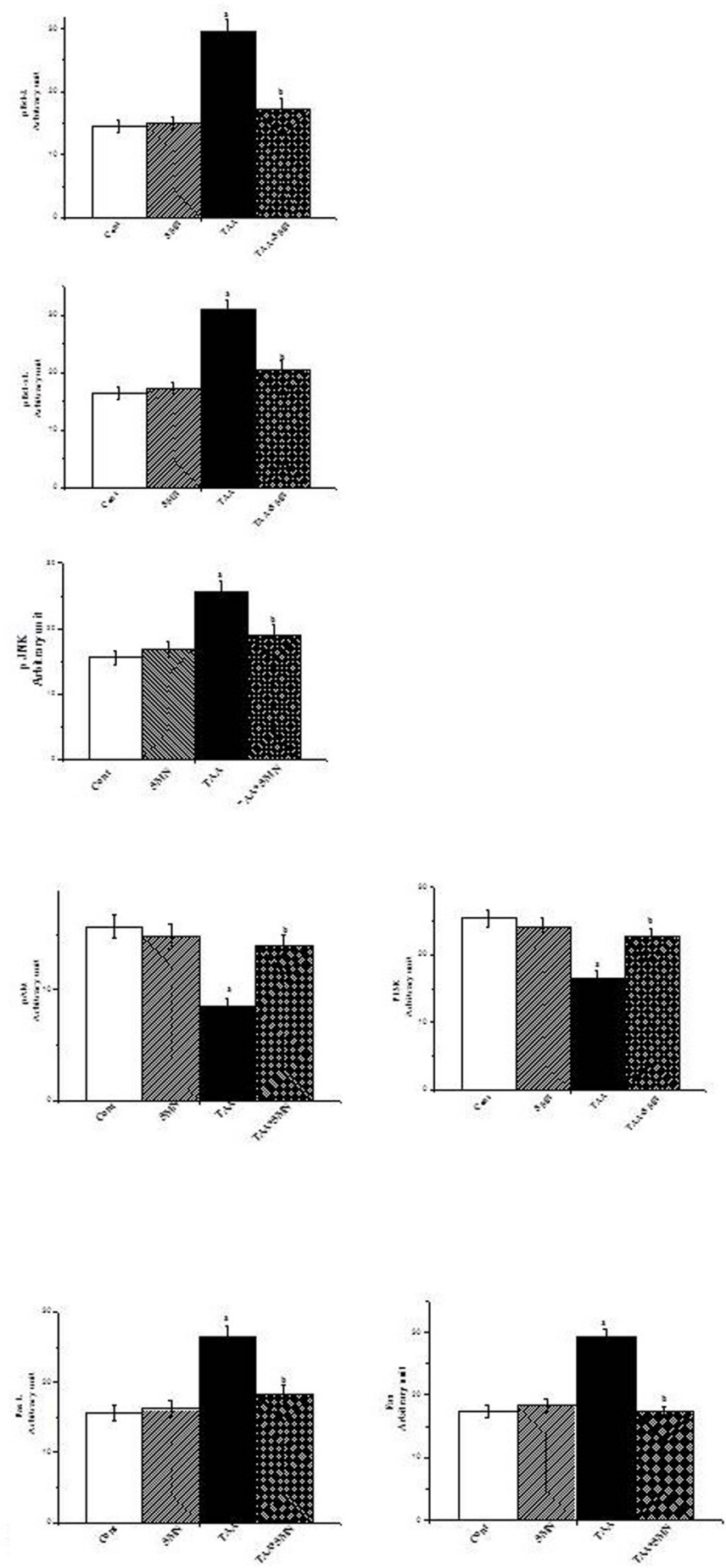

FIGURE 6 | Continued 


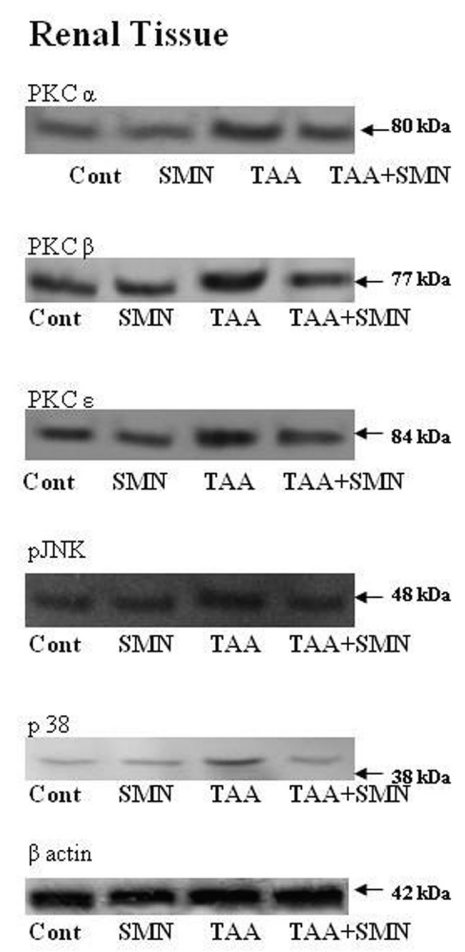

Apoptotic pathway: Liver
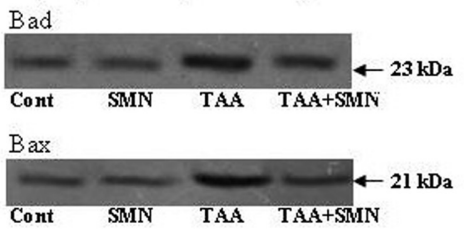

Bcl-2

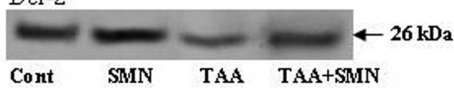

$\mathrm{Bcl}-\mathrm{xL}$

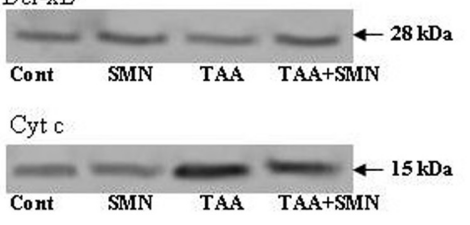

Cleaved caspase 3

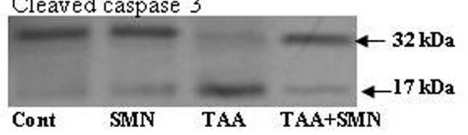

PARP cleavage

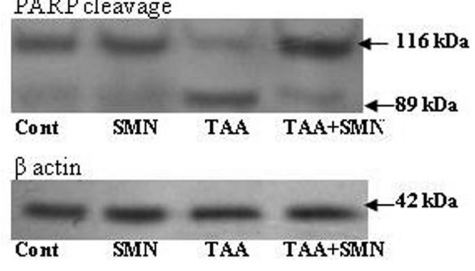

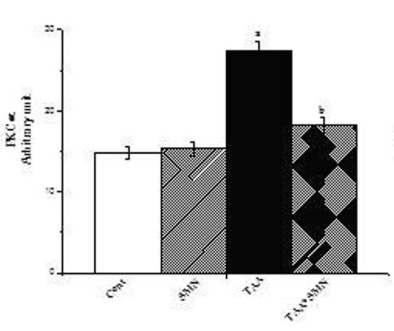
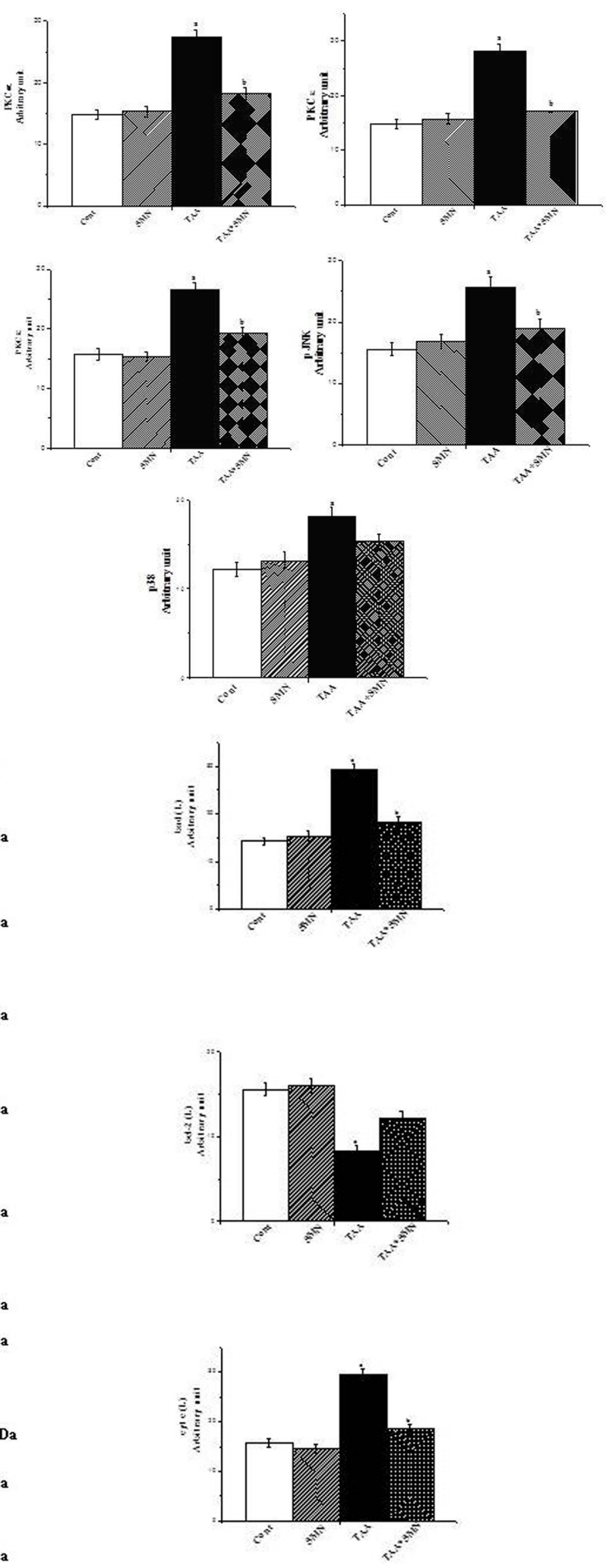

FIGURE 6 | Continued 


\section{Apoptotic pathway: Kidney}
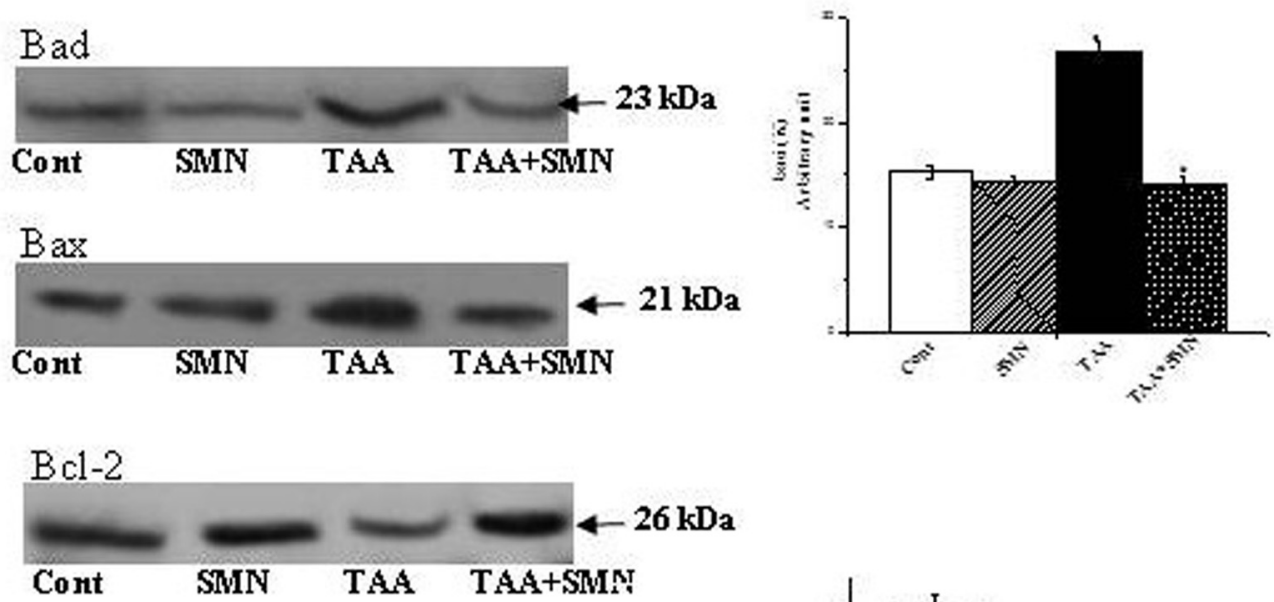

$\mathrm{Bcl}-\mathrm{xL}$

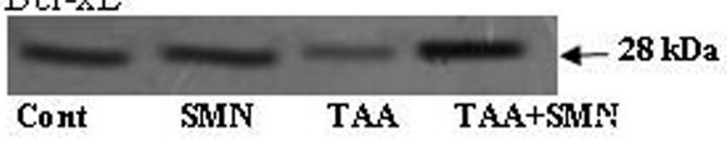

Cyt c
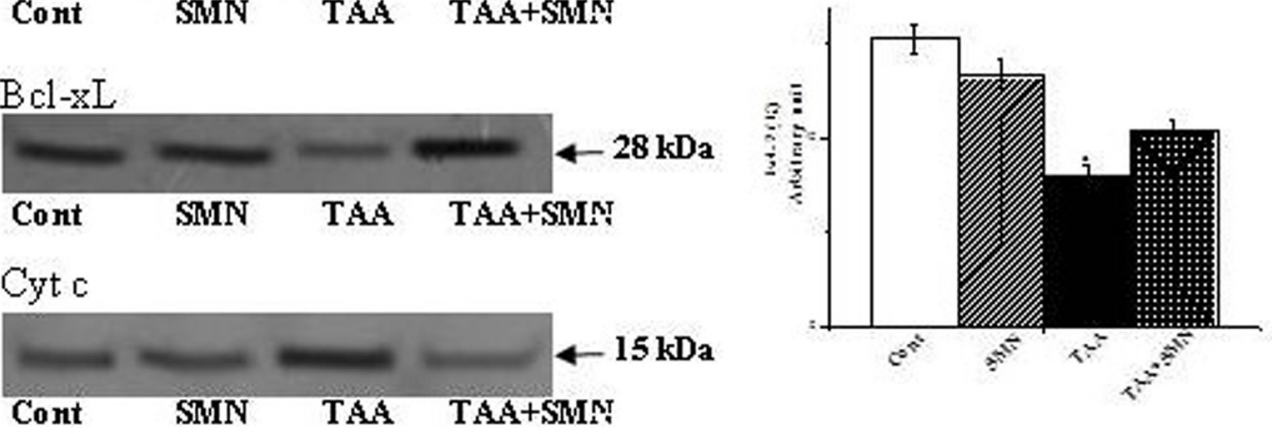

Caspase 3 cleavage

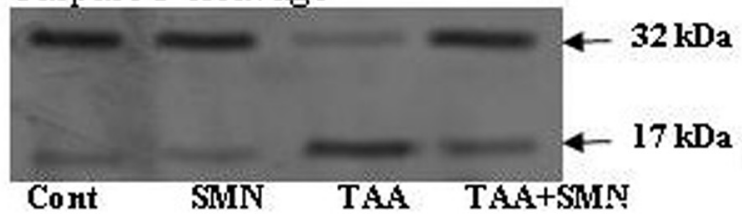

$\beta$-actin
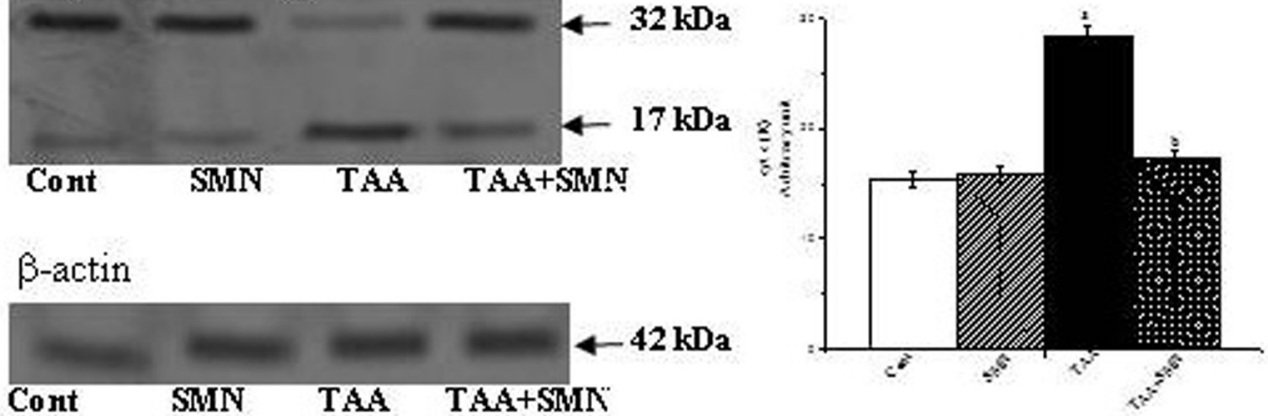

FIGURE 6 | Western blot analysis of different proteins. $\beta$-actin served as a loading control. "a" indicates the significant difference between the normal and TAA-exposed animals liver and kidney tissue homogenates, "b" indicates the significant difference between TAA and SMN+TAA-treated animal tissue homogenates. Each column represents mean \pm SEM, $n=6$ ( $\left.p^{a}<0.05, p^{b}<0.05\right)$.

binding of an extracellular ligand (SMN here) in the plasma membrane. p85 subunit then binds to phosphorylated tyrosine residues on the activated receptor via its $\mathrm{SH} 2$ domain and recruits the p110 forming the fully active PI3K enzyme. Activated PI3K phosphorylates phosphoinositides and forms phosphatidylinositol 3,4,5-triphosphate (PIP3) which facilitates the recruitment of Akt to the plasma membrane. Akt is phosphorylated by phosphoinositide-dependent kinase-1 (PDK1) at Thr308. Full activation of Akt, however, needs phosphorylation at Ser473 as well, by different other proteins like PDK-2, mTORC, etc., activated Akt then phosphorylates downstream molecules like BAD, caspase-9 and consequently initiates apoptosis. In this study, both the levels of PI 3-k and p-Akt levels were reduced in TAA-exposed murine liver compared with the control animals. These alterations in these protein levels due to TAA exposure were attenuated by treatment with SMN because of either increased synthesis or less degradation of these proteins in the presence of SMN (Figure 6). 
TABLE 5 | The product size and annealing temperature of the primers used for Fas, Fas $L$, and actin genes.

\begin{tabular}{llcc}
\hline Gene & $\begin{array}{l}\text { Oligonucleotides used for real-time } \\
\text { polymerase chain reaction (PCR) } \\
\text { primer sequence } \mathbf{5}^{\prime} \text { to } \mathbf{3}^{\prime}\end{array}$ & $\begin{array}{c}\text { Annealing } \\
\text { temperature } \\
\text { (' } \mathbf{C})\end{array}$ & $\begin{array}{c}\text { DNA } \\
\text { bases } \\
\text { (bp) }\end{array}$ \\
\hline Fas & Fp:AGACAGGATGACCCTGAATCTA & 54.7 & 22 \\
\multirow{2}{*}{ Fas L } & Bp:TTCTGCTCAGCTGTGTCTTG & 55.1 & 20 \\
\multirow{2}{*}{ Actin } & Fp:AGATGGGCCCACAGCAG & 54.9 & 17 \\
& Fp:ACATTGGCATGGCTTTGTT & 52.4 & 25 \\
& Bp:GTCCTCAGCCACATTTGTAGA & 53.8 & 20 \\
\hline
\end{tabular}

\section{The Extrinsic Apoptotic Pathway in Hepatocytes}

Literature reveals that high amounts of Fas, a member of the tumor necrosis factor (TNF) receptor superfamily (also known as CD95), are constitutively expressed on the surface of hepatocytes (Schneider et al., 1997; Wang et al., 2010). Fas plays a crucial role in case of many types of liver diseases also. After Fas ligand (FasL) binds to Fas on the cell surface, two apoptotic pathways can be initiated, a direct type I pathway and a mitochondria dependent type II pathway. Type I pathway starts with the formation of the death inducing signaling complex (DISK) at the activated Fas receptor. FasL binding initiates a conformational change. Consequently the intracellular domain of Fas is able

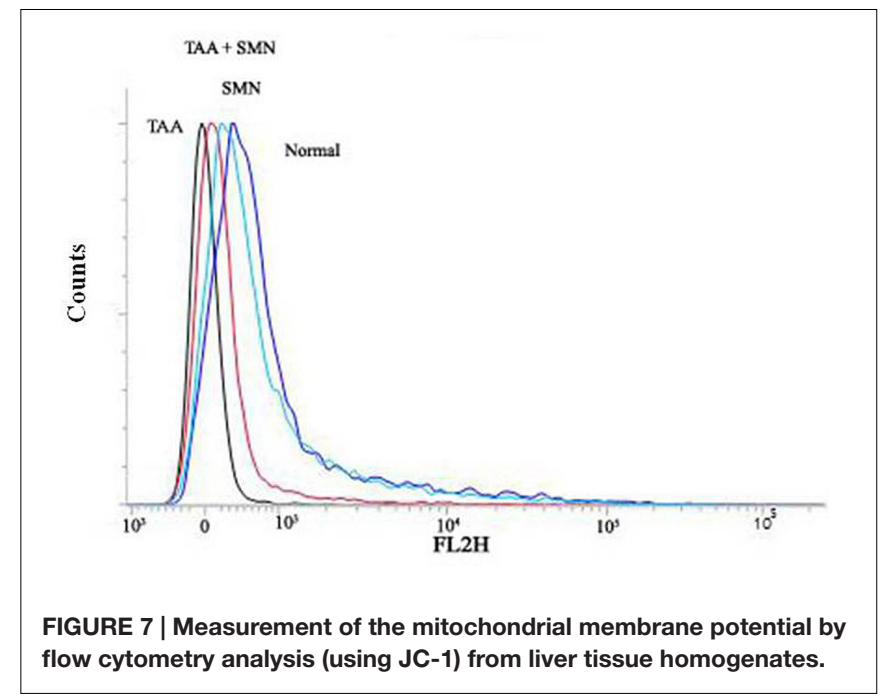

to bind to the adaptor FADD which in turn activates caspase 8 in the cytosol from pro-caspase 8 . Activated caspase 8 then proteolytically degrades pro-caspase 3 to form fully active caspase 3 which then initiates downstream signaling ultimately leading to apoptosis.

To know whether SMN could inhibit the Fas mediated (type I) apoptosis or not, we investigated the expression of capase 8 (at

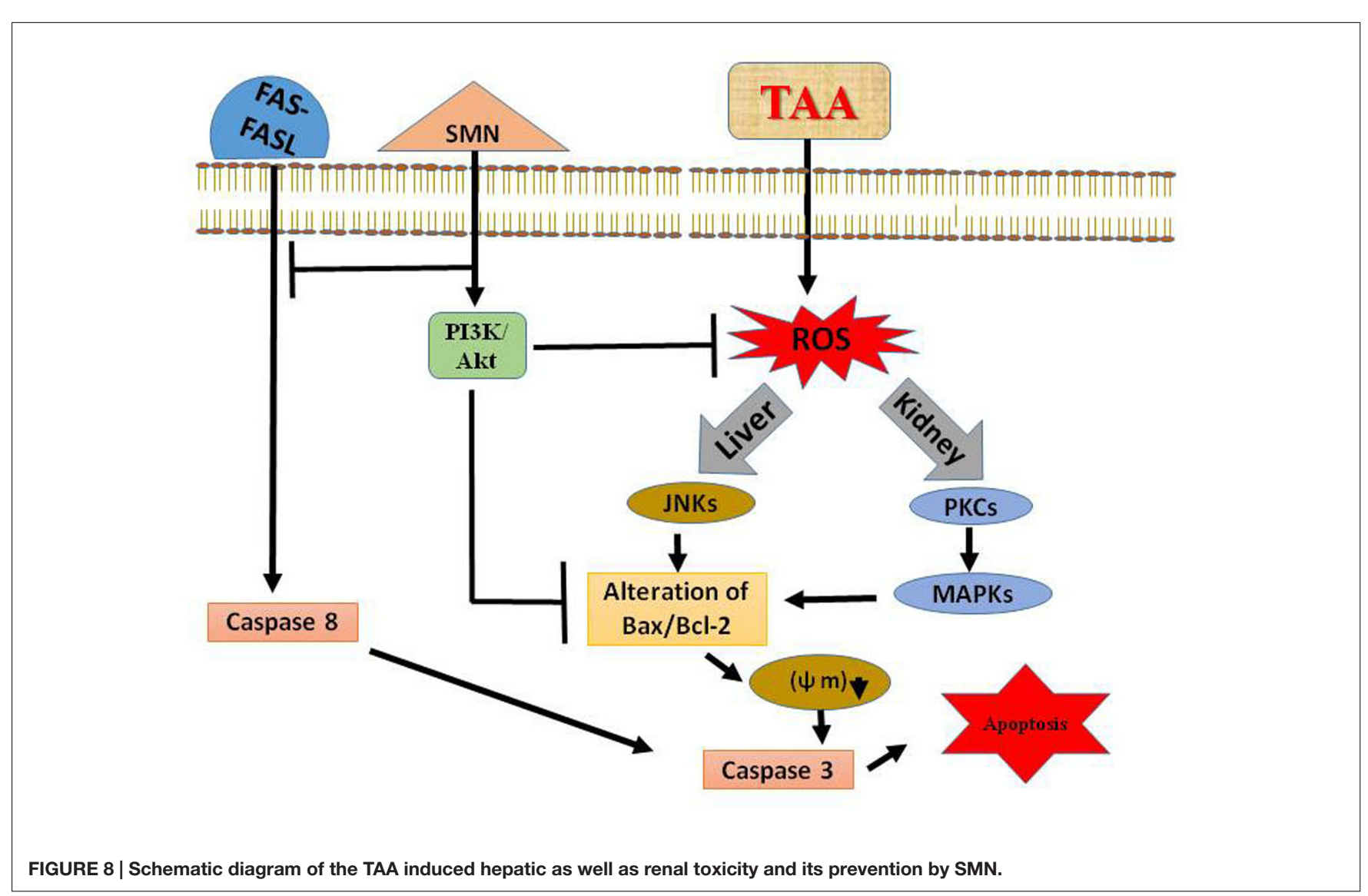


the protein level by western blot) and Fas and FasL (at the mRNA level by RT-PCR) (Table 5). Results showed that both the levels of Fas/FasL and caspase 8 have been suppressed significantly in the SMN post-treatment group, i.e., SMN protected TAA exposed mouse hepatocytes from Fas/FasL and caspase 8 mediated apoptosis effectively (Figure 6).

\section{PKC and MAPKs Mediated Renal Apoptosis}

Next, we have searched about the involvement of ROS in renal dysfunction and the signaling pathways associated. Literature indicated that oxidative stress could induce PKC and MAPKs mediated renal tissue damage leading to apoptosis (Tuttle et al., 2005; Xu et al., 2010). So, we measured the above said signaling molecules quantitatively using western blot assay. The results of our study revealed that TAA exposure indeed increased the expression of different forms of PKC (PKC $\alpha, P K C \beta$, and $\mathrm{PKC} \varepsilon)$ and MAPKs (p38 and JNK). SMN treatment, however, restored their levels toward the normal value and protected the kidney (Figure 6).

\section{Apoptotic Cell Death Pathway both in Case of Liver and Kidney}

Finally, we have investigated the intrinsic apoptotic cell death pathway in liver and renal tissues as TAA exposure might turn on this pathway. Apoptosis is one of the most complex fate of a cell primarily depends on the balance between pro-apoptotic and anti-apoptotic proteins. Apoptosis occurs when this balance is compromised either by the up-regulation of pro-apoptotic proteins and/or down regulation of anti-apoptotic proteins (Hui et al., 2016). The results of our study reveal that TAA increased the expressions of pro-apoptotic proteins, such as Bad and Bax and decreased the expressions of anti-apoptotic proteins $\mathrm{Bcl}-2$ and Bcl-xL. Our results also showed that SMN post-treatment effectively ameliorated all of these anomalies.

In normal, healthy cells, pro-apoptotic protein Bax is present in the cytosol. When apoptotic signal is present, Bax undergoes a conformational change and translocated into the mitochondria and causes damages to the outer mitochondrial membrane causing pores on the mitochondrial outer membrane leading to mitochondrial membrane depolarisation (Gross et al., 1998; Bhattacharyya et al., 2014).

But maintenance of mitochondrial membrane potential $\left(\psi_{\mathrm{m}}\right)$ is crucial for cellular survival as its $\left(\psi_{\mathrm{m}}\right)$ loss induces the release of cytochrome $c$ into the cytosol and activates downstream apoptotic signaling pathways (Sinha et al., 2013). Results of our present study showed that TAA exposure decreased the mitochondrial membrane potential (in hepatocytes) significantly

\section{REFERENCES}

Abdel-Moneim, A. M., Al-Kahtani, M. A., El-Kersh, M. A., and Al-Omair, M. A. (2015). Free radical-scavenging, anti-inflammatory/anti-fibrotic and hepatoprotective actions of taurine and silymarin against $\mathrm{CCl} 4$ induced rat liver damage. PLoS ONE 10:e0144509. doi: 10.1371/journal.pone. 0144509 and SMN could ameliorate this phenomenon effectively (Figure 7). Immunoblot studies also showed that cytosolic cytochrome c level was increased in TAA exposed group compared to normal. SMN post-treatment also protected mice liver and kidney from mitochondrial depolarisation directed cytochrome c release in the cytosol (Figure 6).

After the release into the cytosol, cytochrome $c$ forms apoptosomes that activates caspase 9 and other downstream caspases (Eleftheriadis et al., 2016). In the present study, apoptosis was determined by the estimation of caspase-3 activation and PARP cleavage. Caspase 9 cleaves pro-caspase 3 and forms activated cleaved caspase 3, indicator of caspase-3 activation, which in turn, cleaves PARP and induces subsequent apoptosis (Pal et al., 2015b). Se, we measured the levels of cleaved caspase 3 and PARP. Both of these levels were significantly increased in TAA exposed liver and kidney tissues compared to normal animals. However, normalcy was restored in SMN post-treated group in both the cases. It is worth-mentioning that only SMN was not responsible for either caspase 3 activation or PARP-cleavage as evident from the results of SMN group (Figure 6).

\section{CONCLUSION}

In summary, our study indicates that TAA generates oxidative stress that leads to systematic apoptosis within the liver (via the activation of JNK) and kidney (via PKC and MAPKs mediated molecular signaling pathways). SMN, a well-known antioxidant, might protect those organs by elevating the antioxidant enzyme activities and scavenging ROS as evidenced from biochemical results. Moreover SMN induces PI3K-Akt cell survival pathway in the liver and prevents apoptosis in both the organs (Figure 8). So, we are hopeful about the beneficial role of SMN in ameliorating liver as well as kidney under pathophysiologic conditions.

\section{AUTHOR CONTRIBUTIONS}

Experiment design: SG, AS, SB, and PS. Manuscript writing: SG, AS, SB, and PS. Results analysis: PS, SG, AS, and SB.

\section{ACKNOWLEDGMENT}

The authors are grateful to the Department of Science and Technology (DST), Government of India, and Bose Institute, Kolkata.

Al-Attar, A. M. (2012). Attenuating effect of Ginkgo biloba leaves extract on liver fibrosis induced by thioacetamide in mice. J. Biomed. Biotechnol. 2012:761450. doi: 10.1155/2012/ 761450

Amirtharaj, G. J., Natarajan, S. K., Pulimood, A., Balasubramanian, K. A., Venkatraman, A., and Ramachandran, A. (2016). Role of oxygen free radicals, nitric oxide and mitochondria in mediating cardiac alterations during liver 
cirrhosis induced by thioacetamide. Cardiovasc. Toxicol. doi: 10.1007/s12012016-9371-1 [Epub ahead of print].

Ansil, P. N., Nitha, A., Prabha, S. P., Wills, P. J., Jazaira, V., and Latha, M. S. (2011). Protective effect of Amorphophallus campanulatus (Roxb.) Blume. tuber against thioacetamide induced oxidative stress in rats. Asian Pac. J. Trop. Med. 4, 870-877. doi: 10.1016/S1995-7645(11)60211-3

Barker, E. A., and Smuckler, E. A. (1974). Nonhepatic thioacetamide injury. II. The morphologic features of proximal renal tubular injury. Am. J. Pathol. 74, $575-590$.

Benzie, I. F., and Strain, J. (1999). Ferric reducing/antioxidant power assay: direct measure of total antioxidant activity of biological fluids and modified version for simultaneous measurement of total antioxidant power and ascorbic acid concentration. Methods Enzymol. 299, 15-27. doi: 10.1016/S0076-6879(99) 99005-5

Bhattacharyya, S., Ghosh, S., and Sil, P. C. (2014). Amelioration of aspirin induced oxidative impairment and apoptotic cell death by a novel antioxidant protein molecule isolated from the herb Phyllanthus niruri. PLoS ONE 9:e89026. doi: 10.1371/journal.pone.0089026

Bonaventura, J., Schroeder, W., and Fang, S. (1972). Human erythrocyte catalase: an improved method of isolation and a reevaluation of reported properties. Arch. Biochem. Biophys. 150, 606-617. doi: 10.1016/0003-9861(72)90080-X

Bradford, M. M. (1976). A rapid and sensitive method for the quantitation of microgram quantities of protein utilizing the principle of protein-dye binding. Anal. Biochem. 72, 248-254. doi: 10.1016/0003-2697(76)90527-3

Das, J., Ghosh, J., Manna, P., and Sil, P. C. (2010). Acetaminophen induced acute liver failure via oxidative stress and JNK activation: protective role of taurine by the suppression of cytochrome P450 2E1. Free Radic. Res. 44, 340-355. doi: 10.3109/10715760903513017

Das, J., and Sil, P. C. (2012). Taurine ameliorates alloxan-induced diabetic renal injury, oxidative stress-related signaling pathways and apoptosis in rats. Amino Acids 43, 1509-1523. doi: 10.1007/s00726-012-1225-y

Ding, Z., and Zhuo, L. (2013). Attenuation of hepatic fibrosis by an imidazolium salt in thioacetamide-induced mouse model. J. Gastroenterol. Hepatol. 28, 188-201. doi: 10.1111/j.1440-1746.2012.07265.x

Domenicali, M., Caraceni, P., Giannone, F., Baldassarre, M., Lucchetti, G., Quarta, C., et al. (2009). A novel model of CCl4-induced cirrhosis with ascites in the mouse. J. Hepatol. 51, 991-999. doi: 10.1016/j.jhep.2009. 09.008

Du, K., Williams, C. D., McGill, M. R., and Jaeschke, H. (2014). Lower susceptibility of female mice to acetaminophen hepatotoxicity: role of mitochondrial glutathione, oxidant stress and c-jun $\mathrm{N}$-terminal kinase. Toxicol. Appl. Pharmacol. 281, 58-66. doi: 10.1016/j.taap.2014.09.002

Eleftheriadis, T., Pissas, G., Liakopoulos, V., and Stefanidis, I. (2016). Cytochrome $\mathrm{c}$ as a potentially clinical useful marker of mitochondrial and cellular damage. Front. Immunol. 7:279. doi: 10.3389/fimmu.2016.00279

Ellman, G. L. (1959). Tissue sulfhydryl groups. Arch. Biochem. Biophys. 82, 70-77. doi: 10.1016/0003-9861(59)90090-6

Esterbauer, H., and Cheeseman, K. H. (1990). Determination of aldehydic lipid peroxidation products: malonaldehyde and 4-hydroxynonenal. Methods Enzymol. 186, 407-421. doi: 10.1016/0076-6879(90)86134-H

Flohé, L., and Günzler, W. A. (1984). Assays of glutathione peroxidase. Methods Enzymol. 105, 114-120. doi: 10.1016/S0076-6879(84)05015-1

Gascon-Barré, M., Huet, P.-M., Belgiorno, J., Plourde, V., and Coulombe, P. A. (1989). Estimation of collagen content of liver specimens. Variation among animals and among hepatic lobes in cirrhotic rats. J. Histochem. Cytochem. 37, 377-381. doi: 10.1177/37.3.2465335

Ghosh, J., Das, J., Manna, P., and Sil, P. C. (2010). Arjunolic acid, a triterpenoid saponin, prevents acetaminophen (APAP)-induced liver and hepatocyte injury via the inhibition of APAP bioactivation and JNK-mediated mitochondrial protection. Free Radic. Biol. Med. 48, 535-553. doi: 10.1016/j.freeradbiomed. 2009.11.023

Green, L. C., Wagner, D. A., Glogowski, J., Skipper, P. L., Wishnok, J. S., and Tannenbaum, S. R. (1982). Analysis of nitrate, nitrite, and [15 N] nitrate in biological fluids. Anal. Biochem. 126, 131-138. doi: 10.1016/0003-2697(82) 90118-X

Gross, A., Jockel, J., Wei, M. C., and Korsmeyer, S. J. (1998). Enforced dimerization of BAX results in its translocation, mitochondrial dysfunction and apoptosis. EMBO J. 17, 3878-3885. doi: 10.1093/emboj/17.14.3878
Habig, W. H., Pabst, M. J., and Jakoby, W. B. (1974). Glutathione S-transferases the first enzymatic step in mercapturic acid formation. J. Biol. Chem. 249, 7130-7139.

Hajovsky, H., Hu, G., Koen, Y., Sarma, D., Cui, W., Moore, D. S., et al. (2012). Metabolism and toxicity of thioacetamide and thioacetamide S-oxide in rat hepatocytes. Chem. Res. Toxicol. 25, 1955-1963. doi: 10.1021/tx3002719

Hawkins, P. T., and Stephens, L. R. (2016). Emerging evidence of signalling roles for PI(3,4)P2 in Class I and II PI3K-regulated pathways. Biochem. Soc. Trans. 44, 307-314. doi: 10.1042/BST20150248

Hissin, P. J., and Hilf, R. (1976). A fluorometric method for determination of oxidized and reduced glutathione in tissues. Anal. Biochem. 74, 214-226. doi: 10.1016/0003-2697(76)90326-2

Hodârnâu, A., Dancea, S., and Bârzu, O. (1973). Isolation of highly purified mitochondria from rat pancreas. J. Cell Biol. 59, 222-227. doi: 10.1083/jcb. 59.1.222

Hui, L., Qian, L., Ying, W., Ying-Yi, W., Meng-Ting, C., Hui-Min, H., et al. (2016). Elevated nitric oxide levels associated with hepatic cell apoptosis during liver injury. Hepatol. Res. doi: 10.1111/hepr.12783 [Epub ahead of print].

Jain, N. K., and Singhai, A. K. (2011). Protective effects of Phyllanthus acidus (L.) Skeels leaf extracts on acetaminophen and thioacetamide induced hepatic injuries in Wistar rats. Asian Pac. J. Trop. Med. 4, 470-474. doi: 10.1016/S19957645(11)60128-4

Jiang, X., Tang, X., Zhang, P., Liu, G., and Guo, H. (2014). Cyanidin-3-Obeta-glucoside protects primary mouse hepatocytes against high glucoseinduced apoptosis by modulating mitochondrial dysfunction and the PI3K/Akt pathway. Biochem. Pharmacol. 90, 135-144. doi: 10.1016/j.bcp.2014. 04.018

Kadir, F. A., Othman, F., Abdulla, M. A., Hussan, F., and Hassandarvish, P. (2011). Effect of Tinospora crispa on thioacetamide-induced liver cirrhosis in rats. Indian J. Pharmacol. 43, 64-68. doi: 10.4103/0253-7613.75673

Kim, M. O., Lee, H. S., Chin, Y. W., Moon, D. O., and Ahn, J. S. (2015). Gartanin induces autophagy through JNK activation which extenuates caspasedependent apoptosis. Oncol. Rep. 34, 139-146. doi: 10.3892/or.2015.3948

Kim, S. H., Oh, D. S., Oh, J. Y., Son, T. G., Yuk, D. Y., and Jung, Y. S. (2016). Silymarin prevents restraint stress-induced acute liver injury by ameliorating oxidative stress and reducing inflammatory response. Molecules 21: 443. doi: $10.3390 /$ molecules 21040443

Kornberg, A. (1955). Lactic dehydrogenase of muscle: pyruvate+ DPNH $\leftrightarrows$ Lactate+ DPN. Methods Enzymol. 1, 441-443. doi: 10.1016/0076-6879(55) 01072-0

Kucera, O., Lotkova, H., Krivakova, P., Rousar, T., and Cervinkova, Z. (2006). Model systems for study of toxic injury of hepatocytes in vitro. Cesk. Fysiol. $55,103-110$.

Ledda-Columbano, G. M., Coni, P., Curto, M., Giacomini, L., Faa, G., Oliverio, S., et al. (1991). Induction of two different modes of cell death, apoptosis and necrosis, in rat liver after a single dose of thioacetamide. Am. J. Pathol. 139, 1099-1109.

Letteron, P., Labbe, G., Degott, C., Berson, A., Fromenty, B., Delaforge, M., et al. (1990). Mechanism for the protective effects of silymarin against carbon tetrachloride-induced lipid peroxidation and hepatotoxicity in mice. Evidence that silymarin acts both as an inhibitor of metabolic activation and as a chainbreaking antioxidant. Biochem. Pharmacol. 39, 2027-2034. doi: 10.1016/00062952(90)90625-U

Lim, S., Lee, S. J., Nam, K. W., Kim, K. H., and Mar, W. (2013). Hepatoprotective effects of reynosin against thioacetamide-induced apoptosis in primary hepatocytes and mouse liver. Arch. Pharm. Res. 36, 485-494. doi: 10.1007/ s12272-013-0039-0

Ma, J. Q., Ding, J., Zhang, L., and Liu, C. M. (2014). Hepatoprotective properties of sesamin against CCl4 induced oxidative stress-mediated apoptosis in mice via JNK pathway. Food Chem. Toxicol. 64, 41-48. doi: 10.1016/j.fct.2013. 11.017

Manna, P., Sinha, M., and Sil, P. C. (2013). Protection of arsenic-induced testicular oxidative stress by arjunolic acid. Redox Rep. 13, 67-77. doi: 10.1179/ $135100008 X 259169$

Mannan, R., Misra, V., Misra, S., Singh, P. A., and Dwivedi, M. (2014). A comparative evaluation of scoring systems for assessing necro-inflammatory activity and fibrosis in liver biopsies of patients with chronic viral hepatitis. J. Clin. Diagn. Res. 8, FC08-FC12. doi: 10.7860/JCDR/2014/8704.4718 
Moreira, E., Fontana, L., Periago, J. L., De Medina, F., and Gil, A. (1995). Changes in fatty acid composition of plasma, liver microsomes, and erythrocytes in liver cirrhosis induced by oral intake of thioacetamide in rats. Hepatology 21, 199-206. doi: 10.1016/0270-9139(95)90429-8

Muriel, P., and Mourelle, M. (1990a). Prevention by silymarin of membrane alterations in acute CCI4 liver damage. J. Appl. Toxicol. 10, 275-279. doi: 10.1002/jat.2550100408

Muriel, P., and Mourelle, M. (1990b). The role of membrane composition in ATPase activities of cirrhotic rat liver: effect of silymarin. J. Appl. Toxicol. 10, 281-284. doi: 10.1002/jat.2550100409

Nash, T. (1953). The colorimetric estimation of formaldehyde by means of the Hantzsch reaction. Biochem. J. 55, 416-421. doi: 10.1042/bj0550416

Natarajan, S. K., Basivireddy, J., Ramachandran, A., Thomas, S., Ramamoorthy, P., Pulimood, A. B., et al. (2006a). Renal damage in experimentally-induced cirrhosis in rats: role of oxygen free radicals. Hepatology 43, 1248-1256. doi: 10.1002/hep. 21179

Natarajan, S. K., Thomas, S., Ramamoorthy, P., Basivireddy, J., Pulimood, A. B., Ramachandran, A., et al. (2006b). Oxidative stress in the development of liver cirrhosis: a comparison of two different experimental models. J. Gastroenterol. Hepatol. 21, 947-957. doi: 10.1111/j.1440-1746.2006.04231.x

Pal, S., Ghosh, M., Ghosh, S., Bhattacharyya, S., and Sil, P. C. (2015a). Atorvastatin induced hepatic oxidative stress and apoptotic damage via MAPKs, mitochondria, calpain and caspase12 dependent pathways. Food Chem. Toxicol. 83, 36-47. doi: 10.1016/j.fct.2015.05.016

Pal, S., Sarkar, A., Pal, P. B., and Sil, P. C. (2015b). Protective effect of arjunolic acid against atorvastatin induced hepatic and renal pathophysiology via MAPK, mitochondria and ER dependent pathways. Biochimie 112, 20-34. doi: 10.1016/ j.biochi.2015.02.016

Rawat, S., and Bouchard, M. J. (2015). The hepatitis B virus (HBV) HBx protein activates $\mathrm{AKT}$ to simultaneously regulate $\mathrm{HBV}$ replication and hepatocyte survival. J. Virol. 89, 999-1012. doi: 10.1128/JVI.02440-14

Reina, M., and Martinez, A. (2016). Is silybin the best free radical scavenger compound in silymarin? J. Phys. Chem. B 120, 4568-4578. doi: 10.1021/acs.jpcb. $6 \mathrm{~b} 02807$

Rousar, T., Kucera, O., Krivakova, P., Lotkova, H., Kandar, R., Muzakova, V., et al. (2009). Evaluation of oxidative status in acetaminophen treated rat hepatocytes in culture. Physiol. Res. 58, 239-246.

Saha, S., Rashid, K., Sadhukhan, P., Agarwal, N., and Sil, P. C. (2016). Attenuative role of mangiferin in oxidative stress-mediated liver dysfunction in arsenicintoxicated murines. Biofactors 42, 515-532. doi: 10.1002/biof.1276

Sarkar, A., Ghosh, S., Chowdhury, S., Pandey, B., and Sil, P. C. (2016). Targeted delivery of quercetin loaded mesoporous silica nanoparticles to the breast cancer cells. Biochim. Biophys. Acta 1860, 2065-2075. doi: 10.1016/j.bbagen. 2016.07.001

Schneider, P., Bodmer, J. L., Holler, N., Mattmann, C., Scuderi, P., Terskikh, A., et al. (1997). Characterization of Fas (Apo-1, CD95)-Fas ligand interaction. J. Biol. Chem. 272, 18827-18833. doi: 10.1074/jbc.272.30.18827
Siddhuraju, P., and Becker, K. (2003). Antioxidant properties of various solvent extracts of total phenolic constituents from three different agroclimatic origins of drumstick tree (Moringa oleifera Lam.) leaves. J. Agric. Food Chem. 51, 2144-2155.

Sinha, K., Das, J., Pal, P. B., and Sil, P. C. (2013). Oxidative stress: the mitochondriadependent and mitochondria-independent pathways of apoptosis. Arch. Toxicol. 87, 1157-1180. doi: 10.1007/s00204-013-1034-4

Sinha, M., Manna, P., and Sil, P. C. (2007a). Attenuation of cadmium chloride induced cytotoxicity in murine hepatocytes by a protein isolated from the leaves of the herb Cajanus indicus L. Arch. Toxicol. 81, 397-406. doi: 10.1007/s00204007-0176-7

Sinha, M., Manna, P., and Sil, P. C. (2007b). Aqueous extract of the bark of Terminalia arjuna plays a protective role against sodium-fluoride-induced hepatic and renal oxidative stress. J. Nat. Med. 61, 251-260. doi: 10.1007/ s11418-007-0133-z

Smith, I. K., Vierheller, T. L., and Thorne, C. A. (1988). Assay of glutathione reductase in crude tissue homogenates using 5, 5'-dithiobis (2-nitrobenzoic acid). Anal. Biochem. 175, 408-413. doi: 10.1016/0003-2697(88)90564-7

Suresh, Y., and Das, U. N. (2006). Differential effect of saturated, monounsaturated, and polyunsaturated fatty acids on alloxan-induced diabetes mellitus. Prostaglandins Leukot. Essent. Fatty Acids 74, 199-213. doi: 10.1016/j.plefa. 2005.11.006

Tuttle, K. R., Johnson, E. C., Cooney, S. K., Anderberg, R. J., Johnson, E. K., Clifton, G. D., et al. (2005). Amino acids injure mesangial cells by advanced glycation end products, oxidative stress, and protein kinase C. Kidney Int. 67, 953-968. doi: 10.1111/j.1523-1755.2005.00159.x

Wang, L., Yang, J. K., Kabaleeswaran, V., Rice, A. J., Cruz, A. C., Park, A. Y., et al. (2010). The Fas-FADD death domain complex structure reveals the basis of DISC assembly and disease mutations. Nat. Struct. Mol. Biol. 17, 1324-1329. doi: $10.1038 / \mathrm{nsmb} .1920$

Xu, B., Xu, Z. F., Deng, Y., and Yang, J. H. (2010). Protective effects of chlorpromazine and verapamil against cadmium-induced kidney damage in vivo. Exp. Toxicol. Pathol. 62, 27-34. doi: 10.1016/j.etp.2008.12.009

Zhao, E., Amir, M., Lin, Y., and Czaja, M. J. (2014). Stathmin mediates hepatocyte resistance to death from oxidative stress by down regulating JNK. PLoS ONE 9:e109750. doi: 10.1371/journal.pone.0109750

Conflict of Interest Statement: The authors declare that the research was conducted in the absence of any commercial or financial relationships that could be construed as a potential conflict of interest.

Copyright (C) 2016 Ghosh, Sarkar, Bhattacharyya and Sil. This is an open-access article distributed under the terms of the Creative Commons Attribution License (CC BY). The use, distribution or reproduction in other forums is permitted, provided the original author(s) or licensor are credited and that the original publication in this journal is cited, in accordance with accepted academic practice. No use, distribution or reproduction is permitted which does not comply with these terms. 